\title{
IS4 family goes genomic
}

\section{Daniel De Palmenaer ${ }^{1}$, Patricia Siguier ${ }^{2}$ and Jacques Mahillon*1}

Address: ${ }^{1}$ Laboratoire de microbiologie alimentaire et environnementale, Université catholique de Louvain, Croix du Sud 2/12, B-1348 Louvainla-Neuve, Belgium and '2Laboratoire de microbiologie et génétique moléculaires, Université Paul Sabatier, 118 route de Narbonne, 31062 Toulouse cedex 9, France

Email: Daniel De Palmenaer - daniel.depalmenaer@uclouvain.be; Patricia Siguier - siguier@ibcg.biotoul.fr; Jacques Mahillon* - jacques.mahillon@uclouvain.be

* Corresponding author

Published: 23 January 2008

BMC Evolutionary Biology 2008, 8: 18 doi:10.1 I86/I47|-2।48-8-18
Received: 13 September 2007

Accepted: 23 January 2008

This article is available from: http://www.biomedcentral.com/I47I-2 I48/8/I8

(C) 2008 De Palmenaer et al; licensee BioMed Central Ltd.

This is an Open Access article distributed under the terms of the Creative Commons Attribution License (http://creativecommons.org/licenses/by/2.0), which permits unrestricted use, distribution, and reproduction in any medium, provided the original work is properly cited.

\begin{abstract}
Background: Insertion sequences (ISs) are small, mobile DNA entities able to expand in prokaryotic genomes and trigger important rearrangements. To understand their role in evolution, accurate IS taxonomy is essential. The IS4 family is composed of $\sim 70$ elements and, like some other families, displays extremely elevated levels of internal divergence impeding its classification. The increasing availability of complete genome sequences provides a valuable source for the discovery of additional IS4 elements. In this study, this genomic database was used to update the structural and functional definition of the IS4 family.
\end{abstract}

Results: A total of 227 IS4-related sequences were collected among more than 500 sequenced bacterial and archaeal genomes, representing more than a three fold increase of the initial inventory. A clear division into seven coherent subgroups was discovered as well as three emerging families, which displayed distinct structural and functional properties. The IS4 family was sporadically present in $17 \%$ of analyzed genomes, with most of them displaying single or a small number of IS4 elements. Significant expansions were detected only in some pathogens as well as among certain extremophiles, suggesting the probable involvement of some elements in bacterial and archaeal adaptation and/or evolution. Finally, it should be noted that some IS4 subgroups and two emerging families occurred preferentially in specific phyla or exclusively inside a specific genus.

Conclusion: The present taxonomic update of IS4 and emerging families will facilitate the classification of future elements as they arise from ongoing genome sequencing. Their narrow genomic impact and the existence of both IS-poor and IS-rich thriving prokaryotes suggested that these families, and probably ISs in general, are occasionally used as a tool for genome flexibility and evolution, rather than just representing self sustaining DNA entities.

\section{Background}

Insertion sequences (ISs) are small $(<2.5 \mathrm{~kb})$, generally phenotypically cryptic segments of DNA able to jump, or copy themselves, into various genomic sites with no need for DNA homology [1]. They generally encode no functions other than those involved in their mobility, although elements including additional genes are now being identified $[2,3]$. While almost exclusively restricted to bacterial and archaeal genomes, they are, like eukaryotic transposable elements, involved in a wide variety of biological transactions leading to genome reshuffling and evolution. Indeed, their ability to proliferate within a 
genome provides the potential for homologous recombination-mediated deletions or inversions, and their capacity to transport accessory genes represents an additional contribution to genome flexibility. By affecting gene expression and facilitating the emergence of new gene clusters they play an important role in adaptability of their host. Eventually, horizontal transfer mechanisms such as conjugation allow these IS-mediated sets of genes to cross barriers between strains, species and beyond [4].

The DNA breaks and joins necessary for transposition are catalysed by an element encoded protein referred to as transposase. These proteins determine transposition mechanisms and are now used to lead classification of prokaryotic transposable elements in general. Accordingly, transposases that form a covalent intermediate with DNA are distinguished from those that do not. Additional distinction is provided by protein active-site residues crucial for transposition. These define the five major transposase classes currently established : tyrosine $(\mathrm{Y})$, serine (S), relaxase (Y1) and rolling-circle (Y2) transposases involve covalent intermediates with DNA during transposition, while the fifth class, namely DDE transposases, prompts transposition via direct transesterification reactions [5-7].

DDE transposases display three acidic residues in three distinct regions of their primary sequence, namely regions $\mathrm{N} 2, \mathrm{~N} 3$ and $\mathrm{C} 1$, which harbor the aspartate (D), aspartate (D) and glutamate (E) residues, respectively. Spacers of various lengths separate these regions, but their acidic residues are brought together upon protein folding to form a catalytic triad essential for transposition [8-11].

Prokaryotic DDE transposons (mainly ISs) can move in two different ways, depending on the fate of the donor site. Replicative transposons mobilize a copy of their DNA, leaving the parent site intact, while conservative transposons cut themselves out of the donor molecule in order to paste their DNA into the target [12].

Beyond mechanistic behaviors, each individual IS is characterized by structural features used to fine-tune their classification. A wealth of these data is currently generated with the rising availability of whole genome sequencing projects. As of July 2007, more than 19 different IS families are established based on over 1800 bacterial and archaeal IS sequences [1,13-16]. An IS family can be defined as a collection of elements sharing the same catalytic site structure (with conserved spacers between key residues), an identical genetic organization (e.g. frameshifting in transposase gene), similar arrangements of their ends and uniform target site fates upon insertion. However, not all families are so coherent. This is why some of them (like families IS4 and IS5) are divided into subgroups being composed of a core of closely related elements that can be linked to other members of the family by weaker but still significant similarities.

The IS4 family, like most IS families described so far, contains elements mobilized by DDE transposases performing a 'cut-and-paste' mechanism. The main and almost only hallmarks of this family's transposases are (i) absence of frameshift in the transposase gene and (ii) an $\mathrm{Y}-(2)-\mathrm{R}-(3)-\mathrm{E}-(6)-(\mathrm{K})$ signature (YREK) in region $\mathrm{C} 1$ where the glutamate residue is that of the DDE motif $[1,17]$. Only very few IS4 elements have been studied in detail. IS231A has been shown to transpose in vivo by a 'cut-and-paste' mechanism [18], both in its natural host, Bacillus thuringiensis [19], and in Escherichia coli [20]; and it displays a certain degree of insertion specificity [21]. Both IS10R and IS50R are part of composite transposons $(\operatorname{Tn} 10[22,23]$ and $\operatorname{Tn} 5[24,25]$, respectively) and are the only members for which in vitro systems have been set up. The latter has allowed extensive acquisition of genetic, biochemical, mechanistic and regulation data for these elements. Also, the Tn5 transposase is the only IS4 element for which X-ray crystallographic structure data are available $[9,26]$.

Since the initial definition of family IS4 (based on about 45 elements), other elements were progressively added via ISfinder, the prokaryotic IS database [15]. However, some of them displayed distant resemblance both to existing IS4 members as well as members of other groups such as the IS5 family or ISNCY (IS Not Classified Yet). Some elements even lacked the above mentioned distinguishing protein motifs. It was therefore necessary to perform a systematic screen for related elements in order to gain a more rational view of the organization of the IS4 family.

Here we report an extensive in silico search for IS elements related to family IS4 among more than 500 complete bacterial and archaeal genomes. A total of 227 putative intact IS4-related elements were collected and permitted a detailed update of the IS4 catalogue, together with the description of novel emerging IS families. This allowed the evaluation of their distribution and impact among major prokaryotic phyla. Finally, known transposition mechanisms could be discussed in light of novel primary sequence data.

\section{Results}

\section{Classification process}

The present assignment of families and subgroups is primarily based on transposase and DNA end sequence data. Analysis of transposases was performed by multiple sequence alignments and clustering methods followed by dendrogram construction to set up clusters of related proteins (see Methods). Left and right DNA extremities flank- 
ing transposase genes were aligned (i) to each other to facilitate observation of terminal inverted repeats (TIRs) and (ii) with TIRs from other ISs to detect DNA extremity conservations. Together, these approaches split the initial IS set into ten groups. In each of them, the percentage of residue identity among transposase pairs often varied between $20 \%$ and $50 \%$, highlighting the magnitude of divergence occurring among elements of a same IS group. The length of TIRs ranged from 10 to $40 \mathrm{bp}$ and many of them were imperfect. Comparison of TIRs from different elements of a given IS group uncovered unique and conserved signatures in each of them, illustrating the relationship between the transposase sequence and the IS terminal repeats (Figure 1).

To validate this clustering, established groups were analysed independently for conservation of specific transposase domains as well as length and specificity of target site duplications. Analysis of transposase DDE catalytic regions (N2, N3 and $\mathrm{C} 1)$ revealed a perfect conservation of the DDE motif (Figure 2), while the size and sequence of the spacers that separate these catalytic residues differed among the ten groups. The YREK motif was partially lacking in three groups, where either its tyrosine, arginine or lysine residue was not conserved. According to the definition of IS families, IS groups sharing the same catalytic site structure were assigned together. Seven clusters displayed the complete YREK motif; and were named subgroups IS231, ISH8, IS4Sa, IS4, ISPepr1, IS10 and IS50. The three remaining groups all displayed a distinct variation of the YREK motif and were therefore assigned to different and new families, namely IS701, ISH3 and IS1634, referred as emerging families. Finally, while IS4 family members generated about 10 bp target duplications, i.e. the approximate length of a complete DNA helix turn, those from emerging families displayed direct repeats (DRs) of around five bps, which corresponds approximately to half a DNA helix turn (Figures 1 \&3).

\section{Review of family IS4}

Family IS4 included 153 distinct intact elements. The main hallmarks were the presence of $\mathrm{D}(60 \sim 110) \mathrm{D}(100 \sim 150) \mathrm{E}$ and $\mathrm{Y}(2) \mathrm{R}(3) \mathrm{E}(6) \mathrm{K}$ motifs, single orf encoded transposases and target site duplication lengths corresponding approximately to one DNA helix turn. Considerable diversity was observed at the level of transposase regions (sequence and length) outside catalytic residues, DNA end signatures and target site specificity. The following description of established subgroups will summarize this diversity.

Subgroup IS231 was previously established (reviewed in reference [2]) and was the most coherent one since many transposase pairs displayed sequence identity percentages above 50 (see also Figure 1A). Likewise, their DNA ends are among the most conserved. A clear relationship was observed between transposase and extremity conservation (Additional file 1). This is particularly true for left extremities (conventionally upstream of the transposase gene) where transposase-related conservation extended beyond the TIRs. The IS231 subgroup further distinguished itself by the fact that its members occurred almost exclusively in genomes of phylogenetically close bacteria composing the B. cereus sensu lato group (i.e. B. cereus sensu stricto, B. thuringiensis and $B$. anthracis, see Additional file 1 and Figure 4). As previously shown, an important hallmark is the large size range of its elements (Table 1). A significant fraction of them displayed additional DNA between the left TIR and the transposase gene [2,3], which is still unusual among ISs. In this study, novel putative passenger genes were found in these extra sequences coding for resistance, virulence or metabolism determinants as well as unknown orfs (results not shown). This modular aspect has not yet been observed in other IS families or IS4 subgroups, which may be due to the fact that, so far, no systematic and thorough searches for supplementary IS DNA were carried out in other families.

Subgroup ISH8 was initially included into subgroup IS4Sa [1]. Yet, our results showed a closer proximity to subgroup IS231; not only at the transposase level, but also due to DNA extremity conservations (both displayed conserved 5'-CAT ends, Figure 1B and Additional file 2). ISH8 elements were initially discovered in archaea but recent genome projects uncovered elements of this subgroup in proteobacteria. Examination of ISH8 insertions did not reveal apparent target site specificity, contrary to the one observed for IS231 elements (Figure 3).

\section{Subgroups IS4Sa and IS4.}

This study provided the first thorough description of subgroup IS4Sa that was originally mentioned in reference [1]. Together with IS4Sa-like elements appeared a closely related subgroup including element IS4, which provided the name for this second ensemble. Subgroups IS4Sa and IS4 were relatively close at the protein level and the major argument for splitting them in two was a different organization of TIRs (Figure $1 \mathrm{~B}$ and Additional files 3 \&4). Extremities in subgroups IS4Sa and IS4 displayed relaxed conservation of the third and first nucleotide, respectively, which is rather new but not unique in family IS4 (see below). Some elements of subgroup IS4 displayed spectacular apparent insertion specificity in left and right target arms, a conservation that was also observed for ISRm 22 from subgroup IS4Sa (Figure 3). Both subgroups were quite diverse and broadly distributed in bacteria. Rare occurrences were recorded in archaea (ISFac10) and algae viruses (ISvEsV1_1, see Figure 4 and Additional files 3 and 4 ). 


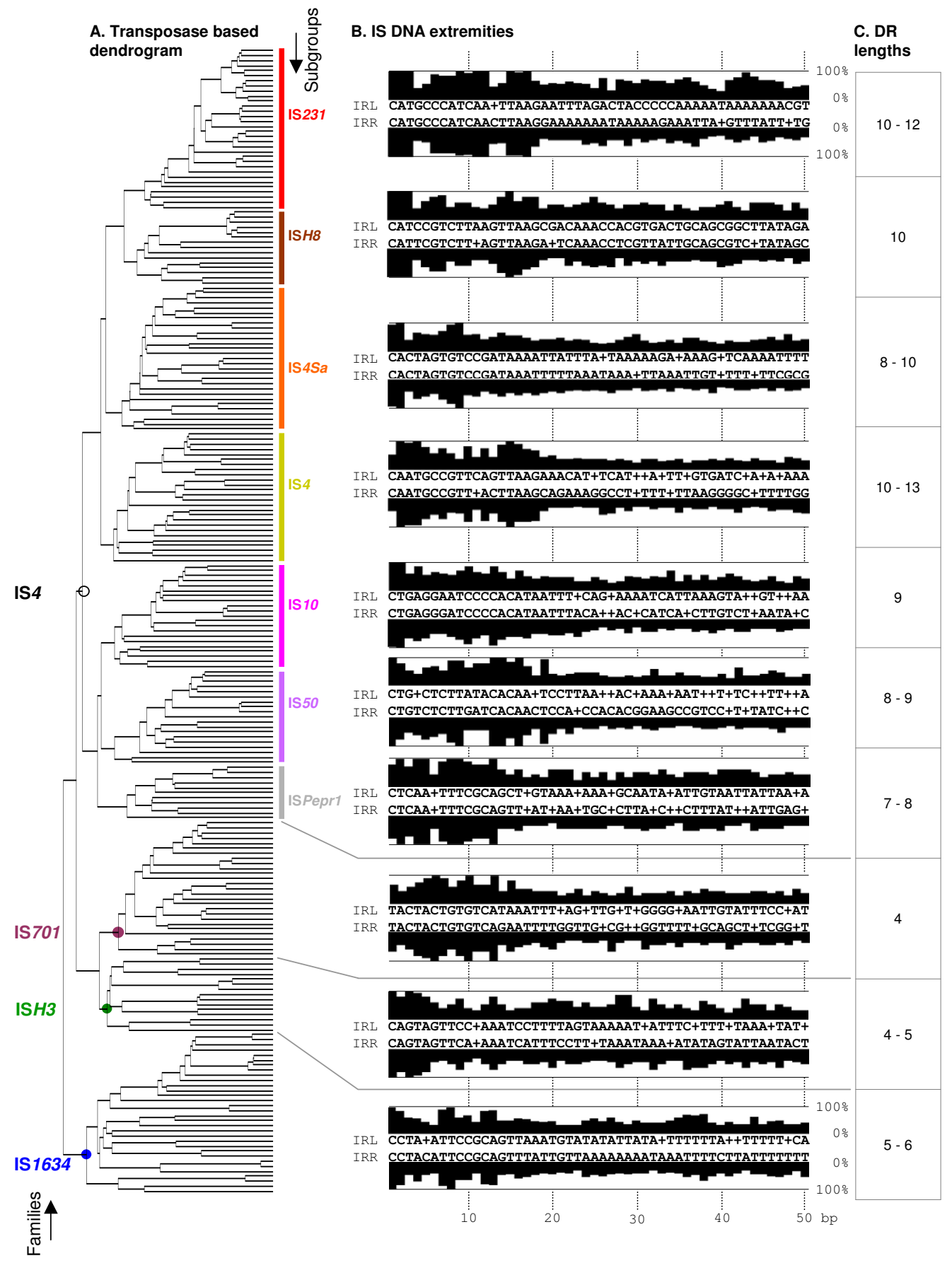

Figure I

Transposases vs. IRs and DRs. Comparative overview of IS sequence features. A. Dendrogram representing an alignment of 227 transposases. The first common node of each family was pointed out on the left tree side. Subgroups of family IS4 are mentioned on the right tree side. Individual IS names were removed for clarity. B. Consensus sequences (5' to 3') of left (upper line) and right (lower line) DNA extremities of distinct subgroups/families. ' + ' symbols are used when the highest conservation level is shared by more than one residue. Percentages of nucleotide conservation at all positions are indicated by black bars. Decimal nucleotide numbering is marked by dotted vertical lines. Full alignments that generated each consensus can be found in Additional files I to I0. Note that in the case of family IS70I, the exposed consensus does not represent the entire family. For further details, see Additional file 8. IRL, left TIR; IRR, right TIR. C. Target duplication length range in bps. 
Families Subgroups
N2

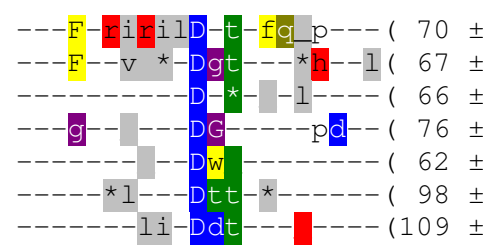

N3

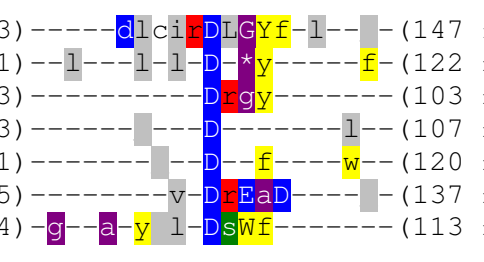

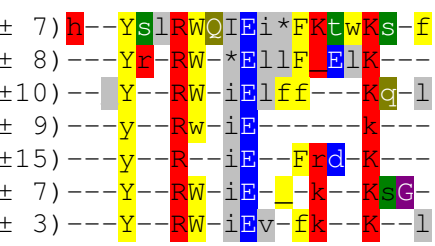

IS 701
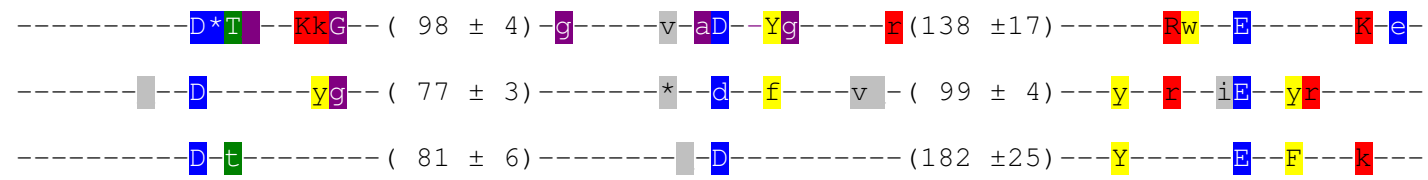

BOLD : DDE

UPPER CASE $:$ Identity $=100 \%$

lower case : $100 \%>$ Identity $\geq 70 \%$

coloured * : $100 \%$ conservation of physicochemical properties

coloured $:<100 \%$ conservation of physicochemical properties

Negative $(\mathrm{D}, \mathrm{E})$

Positive $(\mathrm{K}, \mathrm{R}, \mathrm{H})$

Aromatic $(\mathrm{F}, \mathrm{W}, \mathrm{Y})$

Hydroxyl containing (S,T)
Aliphatic amides (N,Q)

Glycine, Alanine $(G, A)$

Aliphatic (I,L,V)

Cysteine, Proline (C,P)

\section{Figure 2}

DDE and YREK motifs of IS4 subgroups and emerging families. Comparative overview of conserved transposase regions among IS4 subgroups and emerging families. Each line represents a part of the amino acid consensus obtained from multiple alignments of members belonging to the displayed IS groups. Numbers in brackets correspond to the mean amino acid spacer (accompanied by standard deviation) between the two aspartate residues or the aspartate and glutamate residues of the DDE motifs among transposases form a given group. The conserved transposase regions $\mathrm{N} 2, \mathrm{~N} 3$ and $\mathrm{Cl}$ are mentioned on top of alignment. Symbols and colors are used as depicted in keys.

Subgroups IS10 and IS50 were the only ones that did not cluster together with subgroups IS231, ISH8, IS4Sa, IS4 and ISPepr1 during Tribe-MCL analysis (results not shown), indicating more distant relationships with these subgroups. This was also observed at the level of DNA ends since they systematically displayed 5'-NT extremities instead of 5'-NA. Yet, they displayed key residue conservation (Figure 2) and target site duplication lengths comparable to typical IS4 elements (Figures 1 \&3). So far, the majority of both subgroups occurred among proteobacteria.

Subgroup ISPepr1 was also newly established here and is almost exclusively composed of novel elements. Although it is composed of a limited repertoire, it is already forming a consistent subgroup with apparent insertion preference for AT-rich sequences (Figure 3) and, like elements of subgroups IS10 and IS50, it preferentially displays 5'-CT ends (Additional files 5, 6 and 7), in contrast to 5'-CA extremities encountered in the other elements from family IS4.

\section{Emerging families}

Members of Family IS 701 were already considered distantly related to IS4 in reference [1] and this was confirmed here. Only four of the 27 considered IS701 elements displayed the tyrosine of the YREK motif (results not shown, see Figure 2); and almost all elements dis- played a highly conserved target site duplication of exactly four bps (results not shown, see Figure 3). The diversity emanating from IS701 transposases and TIRs allowed identification of three distinct clusters (Additional file 8), which announced a possible division into subgroups. As indicated by their prokaryotic distribution, family IS701 seemed to be rather widespread (Figure 4).

Family ISH3 was a small group so far restricted to archaea (Additional file 9). Half of their transposases lacked the lysine residue of the YREK motif while all (except ISFac10) displayed a Y-(2)-R-(3)-E-(3)-(R) motif. DRs flanking ISH3-like insertions are typically five bps long and generally flanked by A at one end and $\mathrm{T}$ at the other end.

Family IS1634 was initially named IS1549 [1]. This new designation should prevent confusion with an emerging group called IS1595 [13]. Transposases were among the largest due to relatively long N3-C1 spacers, which were sometimes twice as long as those from family IS4. Only five out of 32 displayed the arginine residue of the YREK motif (results not shown, see Figure 2). This large group could be divided in (three) distinct clusters according to transposases (Additional file 10). Target site duplications were five to six bp AT-rich tracts while DNA ends were only poorly conserved. They were remarkably diverse in archaea and relatively widespread in bacteria (Figure 4). 


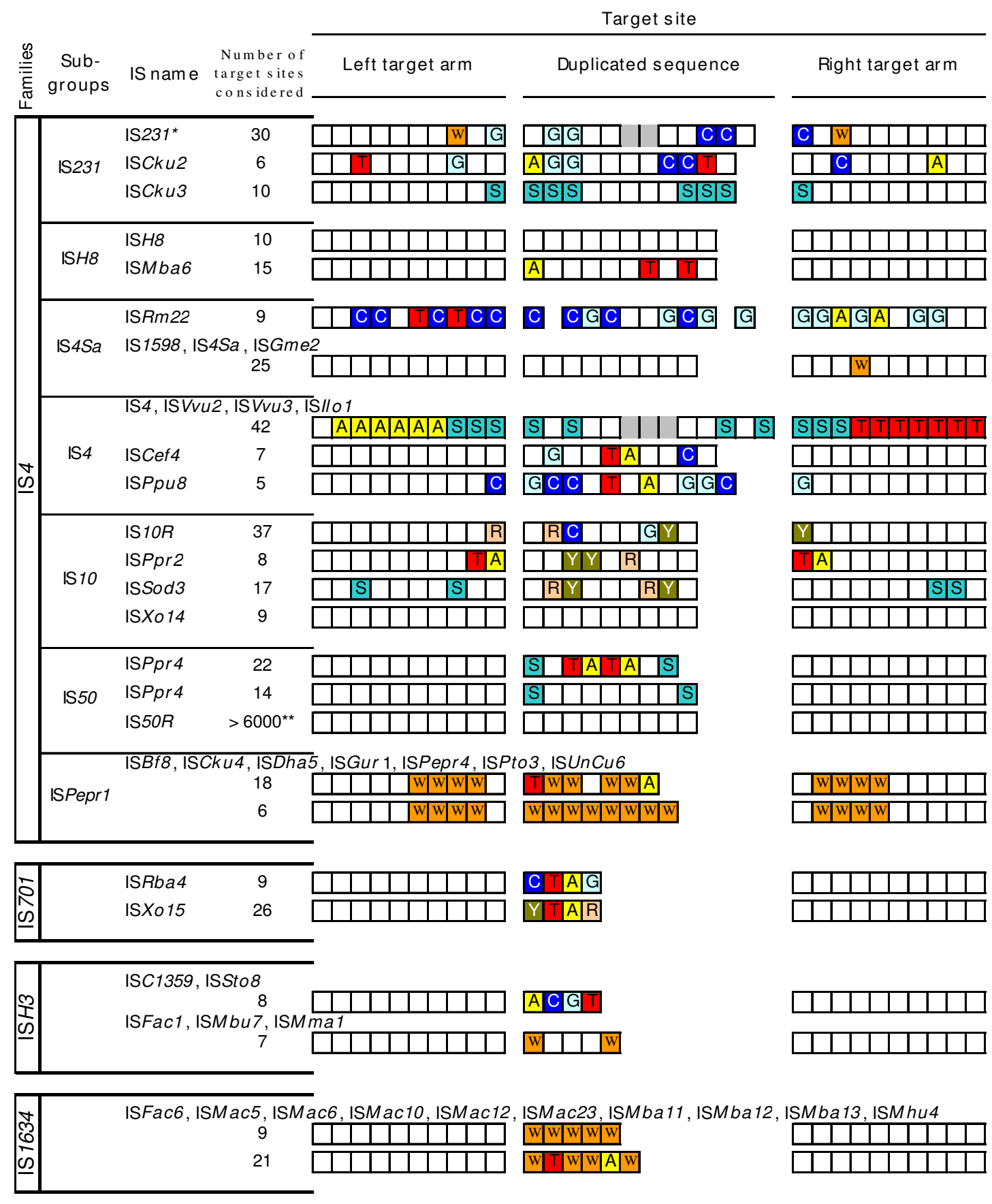

Figure 3

Target sites : duplications and conservations. Consensus sequences of in silico reconstructed and aligned target sites ( $5^{\prime}$ to $3^{\prime}$ ) typical for each subgroup or family. Only ISs found at least at five different genomic locations and flanked by DRs were considered, as well as elements described previously in literature. Each box represents one base position. Target sites are divided in three parts. The central sequence, which is duplicated upon insertion, is flanked by one upstream (left) and one downstream (right) target arm. Ten bps of each arm are shown. The number of target sites considered for each element is indicated. If more than one element displayed similar insertion specificity, their insertion sites were combined into a single line and their names listed above it. Gray boxes inside a duplication consensus indicate that DRs of variable length can be found for the given element. W, A or T; S, G or C; R, A or G; Y, T or C. * 'IS23I' stands for following elements: IS23 IA, C, F, M, S, T, U, $Y$, ISBce4, 5, 6, II, I2 and ISBth5. ** For the 6000 sites, see references [75-77]. 


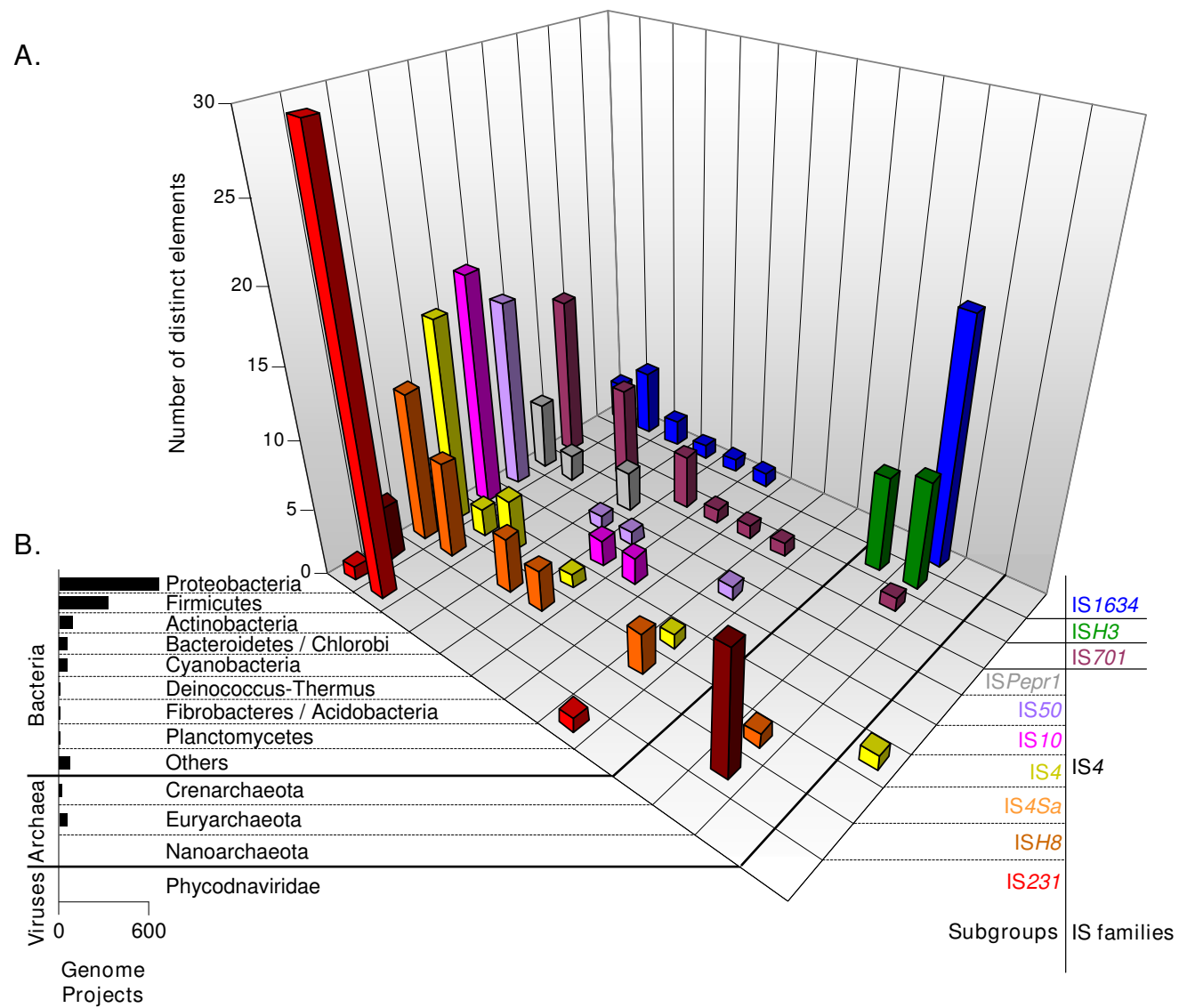

Figure 4

Prokaryote distribution of IS4 subgroups and emerging families. A. Three dimensional histogram of the number of distinct elements belonging to IS4 subgroups and emerging families, as they can be found among major prokaryotic clades. Each IS subgroup/family is represented by a different color. Iso-forms (which we defined as elements that show a divergence of less than $2 \%$ in the amino acid sequence of their potential proteins) were not included. The line 'Others' stands for Aquificae,

Chlamydiae/Verrucomicrobia, Chloroflexi, Chrysiogenetes, Dictyoglomi, Fusobacteria, Nitrospirae, Spirochetes, Thermodesulfobacteria and Thermotogae. For interpretation, see main text. B. To avoid misinterpretation triggered by unequal sequencing efforts between different microbial groups, the number of genome projects, as of I ${ }^{\text {st }}$ April 2007, is depicted by histogram.

Table I: Major features of IS4 subgroups and newly defined families

\begin{tabular}{|c|c|c|c|c|c|}
\hline Families & Sub-groups & Typical size range (bp) & Ends ${ }^{a}$ & YREK ${ }^{b}$ & Direct repeat length (bp) \\
\hline \multirow[t]{7}{*}{ IS4 } & IS23I & $1450-5400$ & CAT ------ AA -- TAA --- & $\mathrm{Y}$ & $10-12$ \\
\hline & ISH8 & $1400-1800$ & $\mathrm{CAT}--------\mathrm{T}-\cdots---$ & Y & 10 \\
\hline & IS4Sa & $1150-1750$ & $\mathrm{CA}------\mathrm{T}---------$ & $Y$ & $8-10$ \\
\hline & IS4 & $1400-1650$ & -AATR-- - - - - WTW - - - & Y & $10-13$ \\
\hline & ISIO & $1200-1350$ & CT ------------- & Y & 9 \\
\hline & IS50 & $1350-1550$ & $C W------Y---C A-A--W-$ & $Y$ & $8-9$ \\
\hline & ISPeprI & $1500-1600$ & YT-AA-YTT-- -A - - - - - & Y & $7-8$ \\
\hline IS70। & - & $1400-1550$ & - - -YACT-Y- -YR- - - - - - & $\mathrm{N}$ & 4 \\
\hline ISH3 & - & $1225-1500$ & CRGT - - - - - - - - - & $\mathrm{N}$ & $4-5$ \\
\hline ISI 634 & - & $1500-2000$ & C--- - YT - - - - - - - - & $\mathrm{N}$ & $5-6$ \\
\hline
\end{tabular}

aConserved terminal based pairs. Capital letters refer to mostly conserved bases. W, A or T; R, G or A; Y, T or C.

bPresence $(Y)$ or absence $(N)$ of YREK motif.

The new organization of family IS4 is shown together with emerging families. The table summarizes DNA characteristics with transposase motifs and target site duplication lengths. The two major differences between IS4 and emerging families are presence or absence of the YREK motif and dissimilar lengths of DRs. 


\section{Distribution of copy numbers}

Members of the IS4 family were found in 92 out of 540 ( $17 \%$ ) complete genomes representing 65 prokaryotic species. Families IS701, ISH3 and IS1634 displayed lower incidences, being present in $\sim 3 \%, \sim 0.7 \%$ and $\sim 2 \%$ of available genomes, respectively. 172 of these genomes included plasmids of which 22 harbored elements of these families. Figure 5 displays the distribution of IS genomic copy numbers as it was found on chromosomes and plasmids. The distribution of family IS4 uncovered a clear preference for single genomic copies, followed by a preference for two, three and six to eight copies per genome. The genomes of Photobacterium profundum SS9, Mycoplasma mycoides subsp. mycoides SC strain PG1, Sulfolobus solfataricus P2 and the two sequenced strains of Xanthomonas oryzae pv. oryzae displayed the highest amounts of elements from families IS4, IS1634, ISH3 and IS701, respectively (Figure 5). The most IS-rich extrachromosomal replicons were megaplasmids pNRC100 (191 $\mathrm{kb})$ and pNRC200 (365 kb) from Halobacterium sp. NRC1 , which harbored together 20 copies of IS4 family elements and 18 copies of family ISH3 elements.

\section{Distribution of IS subgroups and families among prokaryotic phyla and viruses}

The distribution of individual elements among the different bacterial and archaeal phyla is shown in Figure 4. As indicated by the histogram in Figure 4B, current sequencing projects focus unequally on different prokaryotic phyla [27]. The distribution presented in Figure 4A partially reflected this sequencing bias, which is why most gathered elements were found in proteobacteria. Glo-

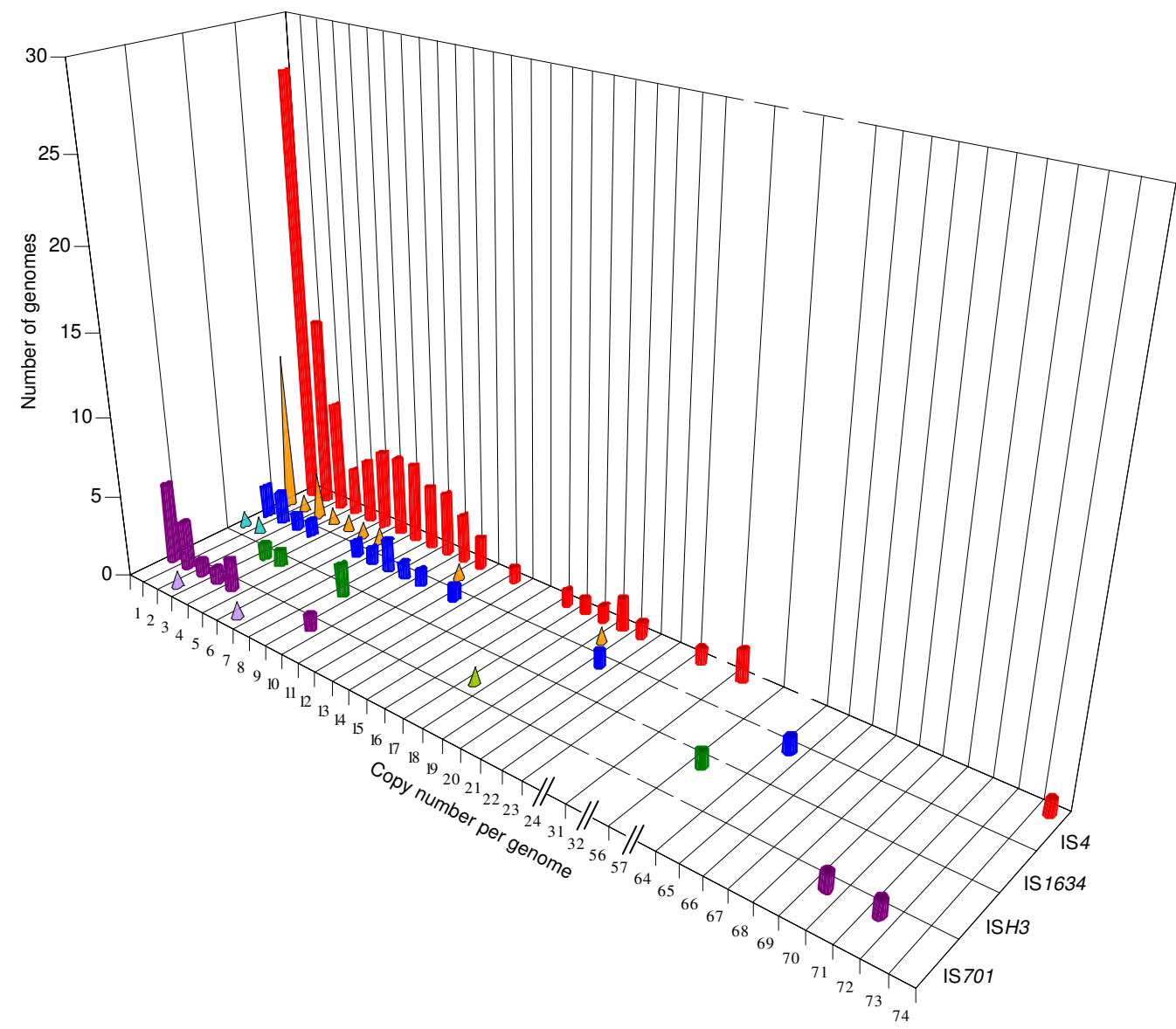

\section{Figure 5}

Genomic IS copy number. Genomic copy numbers of four families as they were found on chromosomes and plasmids. Families IS4, IS I 634, ISH3 and IS70 I are represented in red, blue, green and purple, respectively. The number of copies located on chromosomes is represented by cylinders while those located on plasmids is shown as cones. The height of each cylinder/ cone indicates the number of chromosome/plasmid displaying the corresponding number of IS family members. No distinction was made when different elements of the same IS family occurred in the same genome. The histograms include intact elements, disrupted full length copies and large partial fragments displaying more than $95 \%$ DNA sequence identity. Genomes without any copy of the aforementioned families were not included. 
bally, families IS4, IS701, ISH3 and IS1634 were detected in eight, seven, two and seven phyla, respectively.

Figure $4 \mathrm{~A}$ shows that the distribution of individual IS families or subgroups as defined in this study could either be broad (as for subgroups IS4, IS4Sa and family IS701) or concentrated in a particular phylum (as for subgroup IS231 and family ISH3). Interestingly, two copies of an element belonging to subgroup IS4 were found in the genome of the brown algae virus, Ectocarpus siliculosus virus 1 [28]. So far, no IS4-related element was found in eukaryotes.

\section{Discussion}

Impact of IS4 and related families on prokaryotic genomes The availability of a large number of completely sequenced genomes on one hand, and the extensive manual characterization of an IS family on the other hand, allowed a direct evaluation of global presence of its putatively functional members. Family IS4 displayed a sporadic distribution among $17 \%$ of explored genomes. Moreover, the behavior of these ISs was assessed by determining their genomic occurrence. This showed that numerous elements exhibited single or low copy numbers, which was in line with the assumption that transposable elements need to compromise between transposition for self maintenance and limited insertions to keep host genome integrity [29]. This distribution also displayed a certain, less pronounced, prevalence for copy numbers between 6 and 8, although the biological relevance of this observation remains unclear.

While the global distribution of IS elements was shown to be rather sporadic, important expansion events were observed in a few pathogens as well as in some free-living extremophiles. One of these pathogens is a member of the facultative intracellular Mycoplasma, of which eleven genomes are available. 65 intact copies of family IS1634 elements were found together with 17 intact copies of the IS3 family in M. mycoides [30]. The presence of family IS1634 was also detected in M. synoviae [31], M. agalactiae [GenBank:CU179680] and the three strains of M. hyopneumoniae [31,32]. Only M. genitalium [33], M. pneumoniae [34] and M. mobile [35] were devoid of ISs. Interestingly, the Mycoplasma species lacking ISs were also those displaying the smallest genomes (between 0,58 and $0,82 \mathrm{Mb}$ ), while the IS-rich M. mycoides had a relatively large genome $(1,2 \mathrm{Mbs})$. A positive correlation between the total number of genes and the amount of mobile DNA in a genome has been reported for other facultative intracellular bacteria [36], and a recent study has extended this observation to other prokaryotes [37]. However, this relationship must be seen as a trend with notable exceptions (e.g. the large genome of M. penetrans - 1,36 Mbs - has only 21 transposase genes [38]).
Family IS701 was represented by 70 and 72 elements in the genomes of two sequenced pathovars of the rice pathogen $X$. oryzae $[39,40]$. This family was completely absent in phylogenetically related species with available genome sequences, including $X$. campestris (black rot in crucifers) and X. axonopodis (citrus canker) [39-43]. Additionally, a moderate presence of family IS4 was observed in all but one of the six Xanthomonas genomes (X. campestris pv. vesicatoria), together with other, more expanded families. So far, all sequenced xanthomonads are IS-rich, which is supposed to provide the necessary flexibility for adaptation to different plant hosts [40]. Interestingly, each strain is characterized by the expansion of one specific IS family [43]. The IS4 family was also observed to be relatively expanded in sequenced Shigella spp. where other families, both with higher and lower expansion levels, were also detected [4447]. These mobile elements are supposed to contribute to the emergence of variable epidemiological and pathological features among these phylogenetically close pathogens [45].

These observations are reminiscent of IS expansions observed together with emergence of pathogenicity in other host associated pathogens, such as Bordetella pertussis (whooping cough [48]), Yersinia pestis (plague [49]) and Francisella tularensis (tularemia [50]).

A different relationship was observed in the genus Vibrio. The expansion of family IS4 in the non-pathogenic Photobacterium [51] was striking (Figure 5) as compared to those observed in the pathogenic Vibrionaceae, such as $V$. cholerae [52], V. parahaemolyticus [53] and V. vulnificus [54], that displayed relatively modest IS contents. Therefore, ISs apparently have a quite different role in Vibrio evolution, where some IS-rich species are non-pathogenic piezophiles. Other important IS expansions among freeliving extremophiles were observed in one out of three Sulfolobus spp. [55-57], where family ISH3 represents a significant fraction of global IS content, as well as in Halobacterium, which harbors numerous copies of IS4 and ISH3 elements together with other families [58].

\section{Lateral transfer and clade specificity}

Analysis of the distribution of individual elements among prokaryotes and among established families and subgroups was also performed regardless of copy numbers (Figure 4). Prokaryotic IS hosts were from world-wide origins and covered a large range of lifestyles and habitats, from free-living environmental germs and extremophiles to host associated symbionts and pathogens. Evaluation of emergence on evolutionary timescales, as well as estimation of horizontal gene transfer (HGT) extent prompted by this distribution remain both problematic because of low identity levels among transposases. However, many IS4-related elements were found on putative 
mobile DNA, including various plasmids (Figure 5), bacteriophages (results not shown) and one eukaryotic virus (Figure 4). Additionally, most IS4-related subgroups and emerging families were scattered over several phyla (Additional files $1,2,3,4,5,6,7,8,9,10)$, suggesting an involvement of HGT in the dissemination of these elements.

Reports on prokaryotic IS distribution have shown that IS families are not clade-specific and our data regarding family IS4 were in agreement with this assumption. However, the distribution of IS4 subgroups and emerging families showed that the number of elements of some IS groups was not systematically proportional to the extent of genome sequencing (Figure 4). Subgroup IS231 (family IS4) was almost exclusively restricted to Firmicutes and 26 of its 32 elements were found among bacteria of the $B$. cereus s.l. group. Likewise, family IS1634, and to a lesser extent family ISH3 and subgroup ISH8, were preferentially found among Euryarchaeota. These observations may partially be due to insufficient genome data, but they do not rule out the possibility of existing clade specificity at the level of IS subgroups. Preferential IS occurrences among certain prokaryotic phyla or genera can be the consequence of isolated niches reducing or limiting horizontal transfer of hosted ISs. In this case, a series of extremophilic archaea were almost exclusive hosts of subgroup ISH8 and family ISH3, their preference for harsh ecological niches may represent a frontier for HGT with other phyla or with bacteria. Another possible explanation can be based on IS-associated features. It is possible that the presence of some ISs cannot be tolerated by certain hosts. Uncontrollable transposition behaviors, lack of target site specificity, preferred insertions into vital genes or regulatory regions can limit the host compatibility of some ISs for which a viable equilibrium can be found only in rare 'IS - host' combinations.

\section{Reaction mechanisms}

The co-crystal structure of the IS50R transposase binding the ends of the $\mathrm{Tn} 5$ transposon generated function assignments for numerous residues of this protein [9]. A comparative sequence analysis based on 19 transposases was performed and compared with a previous report on seven transposases from subgroup IS50 by Reznikoff et al. in 2004 [59]. This confirmed the previous function assignment of conserved residues since most identified domains were still conserved among this subgroup, as were a series of residues with unknown function (further results available in Additional file 11).

The primary sequence data concerning the transposase motifs (Figure 2) and target site duplications (Figure 3) suggested divergent biochemical behaviors between IS4 transposases and those from the emerging families. The two 3'-OH transposon ends are known to attack the target helix at opposite sites in the case of IS4. For the emerging families, the length of target site duplications ( $5 \mathrm{bp}$ ) suggested a different target strand cleavage path: owing to the structure of B-DNA, this attack needs to come from the same helix side. It is worth noting that in the case of family IS1634, two elements were reported to display atypical target site duplication lengths. IS1549 and IS1634, from M. smegmatis and M. mycoides, respectively, have both been shown to produce long, variable-length DRs upon insertion $[60,61]$. They had lengths between 8 and 514 bps, depending on the copy. So far, no mechanistic model has been proposed for the generation of this variable target duplication size.

\section{Conclusion}

This study consisted in a thorough and systematic screen for IS4-related elements among available genome sequence data. It allowed a considerable improvement regarding the description and definition of family IS4, as well as the establishment of new IS families which were, until now, assimilated to the IS4 ensemble (Table 1). Thus, 22 distinct IS families are now officially established. Novel primary sequence descriptions were unraveled for reported families, which will allow easier identification of other related elements as they will be uncovered with ongoing genome sequencing projects. This work also established a link between genomic and functional data regarding reaction mechanisms, which underlined the importance of both approaches for a more complete understanding of transposition biology.

The extent of genomic impact of single IS families showed that IS4 and its related families are far from being ubiquitous among prokaryotes. This limited IS distribution applies to most known IS families as reported by a recent automated survey of bacterial ISs [62]. Significant genome wide expansions were observed only in a few host-associated pathogens and certain free-living extremophiles, suggesting that particular ISs could have been, at least partially, implicated in the emergence or evolution of these particular lifestyles. Yet, the reasons explaining these sporadic IS demographic explosions remain to be uncovered.

Our interpretation of these results is that the IS families described here, and probably ISs in general, represent an evolutionary tool available among several. In order to provide the necessary genome flexibility for adaptation to new or variable environments, evolution seems to select this tool in some cases. In contrast to a purely 'selfish' or 'parasitic' perception of mobile DNA, this view supports the idea that prokaryotes, and maybe life in general, may also make use of mobile DNA for its own benefits, rather 
than being constantly invaded by it in an uncontrollable manner.

\section{Methods}

\section{Genomic in silico screen for IS4-like elements}

This search covered more than 500 complete and partial bacterial genomes. Only apparently full-length transposases were retained to avoid inclusion of partially deleted and thus inactivated transposases which can accumulate mutations of functionally important residues.

When we began our search for novel IS4-like elements, the ISfinder database contained about 70 ISs designated as 'member of family IS4'. First, representative elements (about twenty) covering most of the sequence diversity of this family were selected. Primary transposase sequence of each of these representatives was then used in a BLASTP search, either among microbial genomes only, or against all organisms. Since IS4 elements exhibit short TIRs and generate target site duplications upon insertion (DRs), the flanking DNA of resulting hits was checked for the presence of these repeats. This, together with DNA extremity comparison of various elements, allowed the determination of both ends of the collected elements. New ISs were checked for the existence of formerly registered iso-forms which we defined as elements with less than $2 \%$ divergence in the amino acid sequence of their putative transposases and/or less than 5\% difference in their DNA sequences. ISs were submitted to the ISfinder database, which provided new names according to the current IS nomenclature [15].

\section{Bioinformatic procedures}

BLASTP searches were performed on the NCBI BLAST online interface [27] without low complexity filter and with otherwise default parameters. Each transposase sequence retrieved a series of protein hits which were possible transposase candidates. The DNA encoding these candidates was downloaded together with 1000 bps upand downstream regions. These DNA sequences were then verified for the presence of TIRs flanking the transposase candidate genes using BLASTN and the PALINDROME algorithm of the wEMBOSS package at the Belgian EMBnet Node [63]. If TIRs were present, flanking DRs were looked for by eye.

The following multiple alignment algorithms were then evaluated with the resulting ISs for their performance to accurately align the catalytic D, D and E residues of transposases : Clustal W [64], Dialign [65], Parallel PRRN [66], Muscle [67], T-Coffee [68] and M-Coffee [69]. Global alignment of the 227 transposases was made by merging existing M-Coffee alignments with Clustal W. The following order was applied where pre-existing alignments are represented by subgroup or family designations flanked by brackets and merging procedures by + symbols: (((IS231)+(ISH8)+(IS4Sa)+(IS4))+(IS10, IS50, ISPepr1) $)+(($ IS701, ISH3)+(IS1634)). Examination of resulting alignments and subgroup specific dendrogram construction (UPGMA, BLOSUM62) were performed using the Jalview alignment editor [70]. Dendrograms were drawn with TreeView [71].

In order to facilitate visualization of transposase clusters, the TRIBE-MCL clustering algorithm [72] was applied to the complete set of transposases with inflation option (-I) set to 1,2 and default values for other parameters. These settings corresponded to those used by the ISfinder [15] and ACLAME [73] databases.

\section{Evaluation of IS impact on sequenced genomes}

587 chromosomes and 363 plasmids, representing 540 individual completely sequenced bacterial and archaeal genomes, were screened for the presence of IS4, IS701, ISH3 and IS1634 family DNA. Therefore, the 950 molecules were used as input in BLASTN [74] searches against a homemade database containing the 227 DNA sequences encompassing these IS families.

\section{Authors' contributions}

DDP carried out the genomic in silico screen for IS4related elements, aligned DNA and protein sequences of gathered elements, collected insertion sites, proposed the present classification, submitted new elements to the ISfinder database and drafted the manuscript. PS conceived of the IS retrieval strategy, carried out the TribeMCL clustering, participated in analysis and interpretation of data and helped to draft the manuscript. JM participated in design of study and its coordination, participated in interpretation of data and critically revised the manuscript several times. All authors read and approved the final manuscript.

\section{Additional material}

\section{Additional file 1}

Subgroup IS231. A. Dendrogram displaying relative distances of transposases from subgroup IS231. Each tree leave indicates the name of the associated element, followed by the host organism and prokaryotic phylum in which the IS was found originally. For a complete description of individual elements please refer to the ISfinder database [15]. B. and C.

Alignment of left and right DNA extremities, respectively. Names of corresponding elements are listed in the same order as in $A$. The blue color scheme represents the percentage of nucleotide identity per column as displayed by black bars. The DNA extremity consensus used in Figure 1 is shown in bottom, together with minimal (black line) and maximal (dashed line) extent of TIRs. IRL, left TIR; IRR, right TIR.

Click here for file

[http://www.biomedcentral.com/content/supplementary/14712148-8-18-S1.pdf] 


\section{Additional file 2}

Subgroup ISH8. A. Dendrogram displaying relative distances of transposases from subgroup ISH8. Each tree leave indicates the name of the associated element, followed by the host organism and prokaryotic phylum in which the IS was found originally. For a complete description of individual elements please refer to the ISfinder database [15]. B. and C. Alignment of left and right DNA extremities, respectively. Names of corresponding elements are listed in the same order as in A. The blue color scheme represents the percentage of nucleotide identity per column as displayed by black bars. The DNA extremity consensus used in Figure 1 is shown in bottom, together with minimal (black line) and maximal (dashed line) extent of TIRs. IRL, left TIR; IRR, right TIR.

Click here for file

[http://www.biomedcentral.com/content/supplementary/14712148-8-18-S2.pdf]

\section{Additional file 3}

Subgroup IS4Sa. A. Dendrogram displaying relative distances of transposases from subgroup IS4Sa. Each tree leave indicates the name of the associated element, followed by the host organism and prokaryotic phylum in which the IS was found originally. For a complete description of individual elements please refer to the ISfinder database [15]. B. and C. Alignment of left and right DNA extremities, respectively. Names of corresponding elements are listed in the same order as in A. The blue color scheme represents the percentage of nucleotide identity per column as displayed by black bars. The DNA extremity consensus used in Figure 1 is shown in bottom, together with minimal (black line) and maximal (dashed line) extent of TIRs. IRL, left TIR; IRR, right TIR.

Click here for file

[http://www.biomedcentral.com/content/supplementary/14712148-8-18-S3.pdf]

\section{Additional file 4}

Subgroup IS4. A. Dendrogram displaying relative distances of transposases from subgroup IS4. Each tree leave indicates the name of the associated element, followed by the host organism and prokaryotic phylum in which the IS was found originally. For a complete description of individual elements please refer to the ISfinder database [15]. B. and C. Alignment of left and right DNA extremities, respectively. Names of corresponding elements are listed in the same order as in A. The blue color scheme represents the percentage of nucleotide identity per column as displayed by black bars. The DNA extremity consensus used in Figure 1 is shown in bottom, together with minimal (black line) and maximal (dashed line) extent of TIRs. IRL, left TIR; IRR, right TIR.

Click here for file

[http://www.biomedcentral.com/content/supplementary/14712148-8-18-S4.pdf]

\section{Additional file 5}

Subgroup IS10. A. Dendrogram displaying relative distances of transposases from subgroup IS10. Each tree leave indicates the name of the associated element, followed by the host organism and prokaryotic phylum in which the IS was found originally. For a complete description of individual elements please refer to the ISfinder database [15]. B. and C. Alignment of left and right DNA extremities, respectively. Names of corresponding elements are listed in the same order as in A. The blue color scheme represents the percentage of nucleotide identity per column as displayed by black bars. The DNA extremity consensus used in Figure 1 is shown in bottom, together with minimal (black line) and maximal (dashed line) extent of TIRs. IRL, left TIR; IRR, right TIR. Click here for file [http://www.biomedcentral.com/content/supplementary/14712148-8-18-S5.pdf]

\section{Additional file 6}

Subgroup IS50. A. Dendrogram displaying relative distances of transposases from subgroup IS50. Each tree leave indicates the name of the associated element, followed by the host organism and prokaryotic phylum in which the IS was found originally. For a complete description of individual elements please refer to the ISfinder database [15]. B. and C. Alignment of left and right DNA extremities, respectively. Names of corresponding elements are listed in the same order as in A. The blue color scheme represents the percentage of nucleotide identity per column as displayed by black bars. The DNA extremity consensus used in Figure 1 is shown in bottom, together with minimal (black line) and maximal (dashed line) extent of TIRs. IRL, left TIR; IRR, right TIR. Click here for file

[http://www.biomedcentral.com/content/supplementary/14712148-8-18-S6.pdf]

\section{Additional file 7}

Subgroup ISPepr1. A. Dendrogram displaying relative distances of transposases from subgroup ISPepr1. Each tree leave indicates the name of the associated element, followed by the host organism and prokaryotic phylum in which the IS was found originally. For a complete description of individual elements please refer to the ISfinder database [15]. B. and C. Alignment of left and right DNA extremities, respectively. Names of corresponding elements are listed in the same order as in A. The blue color scheme represents the percentage of nucleotide identity per column as displayed by black bars. The DNA extremity consensus used in Figure 1 is shown in bottom, together with minimal (black line) and maximal (dashed line) extent of TIRs. IRL, left TIR; IRR, right TIR. Click here for file [http://www.biomedcentral.com/content/supplementary/14712148-8-18-S7.pdf]

\section{Additional file 8}

Family IS701. A. Dendrogram displaying relative distances of transposases from family IS701. Each tree leave indicates the name of the associated element, followed by the host organism and prokaryotic phylum in which the IS was found originally. For a complete description of individual elements please refer to the ISfinder database [15]. B. and C. Alignment of left and right DNA extremities, respectively. Three distinct alignments, corresponding to three different DNA end signatures, are shown in this case. Names of corresponding elements are listed in the same order as in A. Blue color scheme represents percentage of nucleotide identity per column in each alignment, and is represented by black bars for the upper alignment only. Minimal (black line) and maximal (dashed line) extent of TIRs is given in each case. IRL, left TIR; IRR, right TIR. Click here for file

[http://www.biomedcentral.com/content/supplementary/14712148-8-18-S8.pdf] 


\section{Additional file 9}

Family ISH3. A. Dendrogram displaying relative distances of transposases from family ISH3. Each tree leave indicates the name of the associated element, followed by the host organism and prokaryotic phylum in which the IS was found originally. For a complete description of individual elements please refer to the ISfinder database [15]. B. and C. Alignment of left and right DNA extremities, respectively. Names of corresponding elements are listed in the same order as in A. The blue color scheme represents the percentage of nucleotide identity per column as displayed by black bars. The DNA extremity consensus used in Figure 1 is shown in bottom, together with minimal (black line) and maximal (dashed line) extent of TIRs. IRL, left TIR; IRR, right TIR.

Click here for file

[http://www.biomedcentral.com/content/supplementary/14712148-8-18-S9.pdf]

\section{Additional file 10}

Family IS1634. A. Dendrogram displaying relative distances of transposases from family IS1634. Each tree leave indicates the name of the associated element, followed by the host organism and prokaryotic phylum in which the IS was found originally. For a complete description of individual elements please refer to the ISfinder database [15]. B. and C. Alignment of left and right DNA extremities, respectively. Names of corresponding elements are listed in the same order as in A. The blue color scheme represents the percentage of nucleotide identity per column as displayed by black bars. The DNA extremity consensus used in Figure 1 is shown in bottom, together with minimal (black line) and maximal (dashed line) extent of TIRs. IRL, left TIR; IRR, right TIR.

Click here for file

[http://www.biomedcentral.com/content/supplementary/14712148-8-18-S10.pdf]

\section{Additional file 11}

Combining alignment data from subgroup IS50 with functional data from transposons Tn5. The black sequence is the consensus obtained after multiple alignments of 19 members of the IS50 subgroup with MCOFFEE. Interrupting dashes indicate alignment gaps. The conservation percentage is represented by black bars over each position. The dotted line stands for $70 \%$ residue conservation. Residues of the IS50R transposase with known functional data are shown together with their position coordinates. They are grouped and color-coded following the function they carry out in regulation or during the transposition mechanism. Aspartate and glutamate residues of the DDE motif are pointed out by white triangles among the conservation bars. The YREK motif is highlighted by white ' $V$ '. The transpososome formation step (i) is divided into successive stages including initial cis-binding, dimerization, 3 '-end \& 5 '-end trans binding, trans-

binding via the $\beta$ hairpin clamp and additional trans contacts. Target capture residues are displayed by (ii), while integration and transposase release are not shown. Residues annotated as intramolecular inhibition are supposed to inhibit dimerization of full length transposases. For further details about these mechanistic concepts, see references [9,25,59]. Each residue is linked by colored lines to the corresponding position in the alignment consensus. Their designation is colored and bold if the residue is conserved at least at $70 \%$, gray if it is less or not conserved. Conserved positions with unknown function are pointed out by asterisks $\left({ }^{*}\right)$. Click here for file

[http://www.biomedcentral.com/content/supplementary/14712148-8-18-S11.pdf]

\section{Acknowledgements}

We like to thank Mick Chandler for critically revising this manuscript and for his assistance in finding cozy accommodations in Toulouse. We are also grateful to Bénédicte Laverne for her contribution to the retrieval of useful bioinformatic software as well as towards Bernard Hallet for some fruitful and inspiring discussions. This work was supported by grants from the National Fund for Scientific Research (FNRS, Belgium) as well as the Université catholique de Louvain (UCL).

\section{References}

I. Chandler M, Mahillon J: Insertion Sequences Revisited. In Mobile DNA II Edited by: Craig NL, Craigie R, Gellert M and Lambowitz AM. Washington, D.C., ASMPress; 2002:305-366.

2. De Palmenaer D, Vermeiren C, Mahillon J: IS23I-MIC23I elements from Bacillus cereus sensu lato are modular. Mol Microbiol 2004, 53:457-467.

3. Chen Y, Braathen P, Leonard C, Mahillon J: MIC23I, a naturally occurring mobile insertion cassette from Bacillus cereus. Mol Microbiol 1999, 32:657-668.

4. Ochman H, Lawrence JG, Groisman EA: Lateral gene transfer and the nature of bacterial innovation. Nature 2000, 405:299-304.

5. Ronning DR, Guynet C, Ton-Hoang B, Perez ZN, Ghirlando R, Chandler M, Dyda F: Active site sharing and subterminal hairpin recognition in a new class of DNA transposases. Mol Cell 2005, 20:143-154.

6. Ton-Hoang B, Guynet C, Ronning DR, Cointin-Marty B, Dyda F, Chandler M: Transposition of ISHp608, member of an unusual family of bacterial insertion sequences. Embo J 2005, 24:3325-3338.

7. Curcio MJ, Derbyshire KM: The outs and ins of transposition: from mu to kangaroo. Nat Rev Mol Cell Biol 2003, 4:865-877.

8. Rice P, Mizuuchi K: Structure of the bacteriophage Mu transposase core: a common structural motif for DNA transposition and retroviral integration. Cell 1995, 82:209-220.

9. Davies DR, Goryshin IY, Reznikoff WS, Rayment I: Three-dimensional structure of the Tn5 synaptic complex transposition intermediate. Science 2000, 289:77-85.

10. Haren L, Ton-Hoang B, Chandler M: Integrating DNA: transposases and retroviral integrases. Annu Rev Microbiol 1999, 53:245-28I.

II. Kulkosky J, Jones KS, Katz RA, Mack JP, Skalka AM: Residues critical for retroviral integrative recombination in a region that is highly conserved among retroviral/retrotransposon integrases and bacterial insertion sequence transposases. Mol Cell Biol 1992, 1 2:2331-2338.

12. Craig NL: Unity in transposition reactions. Science 1995 270:253-254.

13. Filee J, Siguier $P$, Chandler $M$ : Insertion sequence diversity in archaea. Microbiol Mol Biol Rev 2007, 7I:121-157.

14. Mahillon J, Chandler M: Insertion sequences. Microbiol Mol Biol Rev 1998, 62:725-774.

15. The ISfinder Database [http://www-is.biotoul.fr]

16. Siguier P, Perochon J, Lestrade L, Mahillon J, Chandler M: ISfinder: the reference centre for bacterial insertion sequences. Nucleic Acids Res 2006, 34:D32-6.

17. Rezsohazy R, Hallet B, Delcour J, Mahillon J: The IS4 family of insertion sequences: evidence for a conserved transposase motif. Mol Microbiol 1993, 9:1283-1295.

18. Leonard C, Mahillon J: IS23 IA transposition: conservative versus replicative pathway. Res Microbiol 1998, I 49:549-555.

19. Mahillon J, Rezsöhazy R, Hallet B, Delcour J: IS23 I and other Bacillus thuringiensis transposable elements: a review. Genetica 1994, 93: 13-26.

20. Hallet B, Rezsöhazy R, Delcour J: IS23 I A from Bacillus thuringiensis is functional in Escherichia coli: transposition and insertion specificity. J Bacteriol | 991, 173:4526-4529.

2I. Hallet B, Rezsöhazy R, Mahillon J, Delcour J: IS23 I A insertion specificity: consensus sequence and DNA bending at the target site. Mol Microbiol 1994, I 4: I3 |-139.

22. Haniford D: Transposon Tn I 0. In Mobile DNA II Edited by: Craig NL, Craigie R, Gellert M and Lambowitz AM. Washington, D.C., ASM Press; 2002:457-483. 
23. Kleckner N: Transposon Tn I 0. In Mobile DNA Edited by: Berg DE and Howe MM. Washington, D.C., American Society for Microbiology; 1989:227-268.

24. Berg DE: Transposon Tn5. In Mobile DNA Edited by: Berg DE and Howe MM. Washington, D.C., Amercian Society for Microbiology; 1989:185-210.

25. Reznikoff WS: Tn5 Transposition. In Mobile DNA // Edited by: Craig NL, Craigie R, Gellert M and Lambowitz AM. Washington, D.C., ASM Press; 2002:403-421.

26. Lovell S, Goryshin IY, Reznikoff WR, Rayment I: Two-metal active site binding of a Tn5 transposase synaptic complex. Nat Struct Biol 2002, 9:278-28I.

27. National Center for Biotechnology Information (NCBI) [http://www.ncbi.nlm.nih.gov/]

28. Filee J, Siguier P, Chandler M: I am what I eat and I eat what I am: acquisition of bacterial genes by giant viruses. Trends Genet 2007, 23:10-15.

29. Nagy Z, Chandler M: Regulation of transposition in bacteria. Res Microbiol 2004, I 55:387-398.

30. Westberg J, Persson A, Holmberg A, Goesmann A, Lundeberg J Johansson KE, Pettersson $B$, Uhlen $M$ : The genome sequence of Mycoplasma mycoides subsp. mycoides SC type strain PG IT, the causative agent of contagious bovine pleuropneumonia (CBPP). Genome Res 2004, I 4:22I-227.

31. Vasconcelos AT, Ferreira HB, Bizarro CV, Bonatto SL, Carvalho MO, Pinto PM, Almeida DF, Almeida LG, Almeida R, Alves-Filho L, Assuncao EN, Azevedo VA, Bogo MR, Brigido MM, Brocchi M, Burity HA, Camargo AA, Camargo SS, Carepo MS, Carraro DM, de Mattos Cascardo JC, Castro LA, Cavalcanti G, Chemale G, Collevatti RG, Cunha CW, Dallagiovanna B, Dambros BP, Dellagostin OA, Falcao C, Fantinatti-Garboggini F, Felipe MS, Fiorentin L, Franco GR, Freitas NS Frias D, Grangeiro TB, Grisard EC, Guimaraes CT, Hungria M, Jardim SN, Krieger MA, Laurino JP, Lima LF, Lopes MI, Loreto EL, Madeira HM, Manfio GP, Maranhao AQ, Martinkovics CT, Medeiros SR Moreira MA, Neiva M, Ramalho-Neto CE, Nicolas MF, Oliveira SC, Paixao RF, Pedrosa FO, Pena SD, Pereira M, Pereira-Ferrari L, Piffer I, Pinto LS, Potrich DP, Salim AC, Santos FR, Schmitt R, Schneider MP Schrank A, Schrank IS, Schuck AF, Seuanez HN, Silva DW, Silva R, Silva SC, Soares CM, Souza KR, Souza RC, Staats CC, Steffens MB Teixeira SM, Urmenyi TP, Vainstein MH, Zuccherato LW, Simpson AJ, Zaha A: Swine and poultry pathogens: the complete genome sequences of two strains of Mycoplasma hyopneumoniae and a strain of Mycoplasma synoviae. J Bacteriol 2005, I 87:5568-5577.

32. Minion FC, Lefkowitz El, Madsen ML, Cleary BJ, Swartzell SM Mahairas GG: The genome sequence of Mycoplasma hyopneumoniae strain 232 , the agent of swine mycoplasmosis. J Bacteriol 2004, I86:7|23-7|33.

33. Fraser CM, Gocayne JD, White O, Adams MD, Clayton RA, Fleischmann RD, Bult CJ, Kerlavage AR, Sutton G, Kelley JM, Fritchman RD, Weidman JF, Small KV, Sandusky M, Fuhrmann J, Nguyen D, Utterback TR, Saudek DM, Phillips CA, Merrick JM, Tomb JF, Dougherty BA, Bott KF, Hu PC, Lucier TS, Peterson SN, Smith HO, Hutchison CA 3rd, Venter JC: The minimal gene complement of Mycoplasma genitalium. Science 1995, 270:397-403.

34. Himmelreich $\mathrm{R}$, Plagens $\mathrm{H}$, Hilbert $\mathrm{H}$, Reiner $\mathrm{B}$, Herrmann $\mathrm{R}$ : Comparative analysis of the genomes of the bacteria Mycoplasma pneumoniae and Mycoplasma genitalium. Nucleic Acids Res 1997, 25:70|-7|2.

35. Jaffe JD, Stange-Thomann N, Smith C, DeCaprio D, Fisher S, Butler J, Calvo S, Elkins T, FitzGerald MG, Hafez N, Kodira CD, Major J, Wang S, Wilkinson J, Nicol R, Nusbaum C, Birren B, Berg HC, Church GM: The complete genome and proteome of Mycoplasma mobile. Genome Res 2004, I4:|447-|46I.

36. Bordenstein SR, Reznikoff WS: Mobile DNA in obligate intracellular bacteria. Nat Rev Microbiol 2005, 3:688-699.

37. Touchon M, Rocha EP: Causes of insertion sequences abundance in prokaryotic genomes. Mol Biol Evol 2007, 24:969-98I.

38. Sasaki Y, Ishikawa J, Yamashita A, Oshima K, Kenri T, Furuya K, Yoshino C, Horino A, Shiba T, Sasaki T, Hattori M: The complete genomic sequence of Mycoplasma penetrans, an intracellular bacterial pathogen in humans. Nucleic Acids Res 2002, 30:5293-5300

39. Lee BM, Park YJ, Park DS, Kang HW, Kim JG, Song ES, Park IC, Yoon UH, Hahn JH, Koo BS, Lee GB, Kim H, Park HS, Yoon KO, Kim JH Jung $\mathrm{CH}$, Koh $\mathrm{NH}$, Seo JS, Go SJ: The genome sequence of $\mathbf{X a n -}$ thomonas oryzae pathovar oryzae KACCI033I, the bacterial blight pathogen of rice. Nucleic Acids Res 2005, 33:577-586.

40. Ochiai H, Inoue $Y$, Takeya M, Sasaki A, Kaku H: Genome sequence of Xanthomonas oryzae pv. oryzae suggests contribution of large numbers of effector genes and insertion sequences to its race diversity. Japan Agricultural Research Quarterly 2005, 39:275-287.

4I. Qian W, Jia Y, Ren SX, He YQ, Feng JX, Lu LF, Sun Q, Ying G, Tang DJ, Tang $H$, Wu W, Hao P, Wang L, Jiang BL, Zeng S, Gu WY, Lu G, Rong L, Tian Y, Yao Z, Fu G, Chen B, Fang R, Qiang B, Chen Z, Zhao GP, Tang JL, He C: Comparative and functional genomic analyses of the pathogenicity of phytopathogen Xanthomonas campestris pv. campestris. Genome Res 2005, I 5:757-767.

42. da Silva AC, Ferro JA, Reinach FC, Farah CS, Furlan LR, Quaggio RB, Monteiro-Vitorello CB, Van Sluys MA, Almeida NF, Alves LM, do Amaral AM, Bertolini MC, Camargo LE, Camarotte G, Cannavan F, Cardozo J, Chambergo F, Ciapina LP, Cicarelli RM, Coutinho LL, Cursino-Santos JR, El-Dorry H, Faria JB, Ferreira AJ, Ferreira RC, Ferro MI, Formighieri EF, Franco MC, Greggio CC, Gruber A, Katsuyama AM, Kishi LT, Leite RP, Lemos EG, Lemos MV, Locali EC, Machado MA, Madeira AM, Martinez-Rossi NM, Martins EC, Meidanis J, Menck CF, Miyaki CY, Moon DH, Moreira LM, Novo MT, Okura VK, Oliveira MC, Oliveira VR, Pereira HA, Rossi A, Sena JA, Silva C, de Souza RF, Spinola LA, Takita MA, Tamura RE, Teixeira EC, Tezza RI, Trindade dos Santos M, Truffi D, Tsai SM, White FF, Setubal JC, Kitajima JP: Comparison of the genomes of two Xanthomonas pathogens with differing host specificities. Nature 2002 , 41 7:459-463.

43. Thieme F, Koebnik R, Bekel T, Berger C, Boch J, Buttner D, Caldana C, Gaigalat L, Goesmann A, Kay S, Kirchner O, Lanz C, Linke B, McHardy AC, Meyer F, Mittenhuber G, Nies DH, Niesbach-Klosgen U, Patschkowski T, Ruckert C, Rupp O, Schneiker S, Schuster SC Vorholter FJ, Weber E, Puhler A, Bonas U, Bartels D, Kaiser O: Insights into genome plasticity and pathogenicity of the plant pathogenic bacterium Xanthomonas campestris pv. vesicatoria revealed by the complete genome sequence. J Bacteriol 2005, I 87:7254-7266.

44. Wei J, Goldberg MB, Burland V, Venkatesan MM, Deng W, Fournier G, Mayhew GF, Plunkett G 3rd, Rose DJ, Darling A, Mau B, Perna NT, Payne SM, Runyen-Janecky LJ, Zhou S, Schwartz DC, Blattner FR: Complete genome sequence and comparative genomics of Shigella flexneri serotype 2 a strain 2457 . Infect Immun 2003, 7I:2775-2786.

45. Yang $F$, Yang J, Zhang $X$, Chen L, Jiang $Y$, Yan $Y$, Tang $X$, Wang J, Xiong Z, Dong J, Xue Y, Zhu Y, Xu X, Sun L, Chen S, Nie H, Peng J, Xu J, Wang Y, Yuan Z, Wen Y, Yao Z, Shen Y, Qiang B, Hou Y, Yu J, jin Q: Genome dynamics and diversity of Shigella species, the etiologic agents of bacillary dysentery. Nucleic Acids Res 2005, 33:6445-6458.

46. Nie H, Yang F, Zhang X, Yang J, Chen L, Wang J, Xiong Z, Peng J, Sun L, Dong J, Xue Y, Xu X, Chen S, Yao Z, Shen Y, Jin Q: Complete genome sequence of Shigella flexneri $5 b$ and comparison with Shigella flexneri 2a. BMC Genomics 2006, 7:173.

47. Jin Q, Yuan Z, Xu J, Wang Y, Shen Y, Lu W, Wang J, Liu H, Yang J, Yang F, Zhang X, Zhang J, Yang G, Wu H, Qu D, Dong J, Sun L, Xue $Y$, Zhao A, Gao Y, Zhu J, Kan B, Ding K, Chen S, Cheng H, Yao Z, He $B$, Chen R, Ma D, Qiang B, Wen Y, Hou Y, Yu J: Genome sequence of Shigella flexneri 2a: insights into pathogenicity through comparison with genomes of Escherichia coli KI 2 and 0 I 57. Nucleic Acids Res 2002, 30:4432-444I.

48. Parkhill J, Sebaihia M, Preston A, Murphy LD, Thomson N, Harris DE, Holden MT, Churcher CM, Bentley SD, Mungall KL, Cerdeno-Tarraga AM, Temple L, James K, Harris B, Quail MA, Achtman M, Atkin R, Baker S, Basham D, Bason N, Cherevach I, Chillingworth T, Collins M, Cronin A, Davis P, Doggett J, Feltwell T, Goble A, Hamlin N, Hauser $H$, Holroyd S, Jagels K, Leather S, Moule S, Norberczak H, O'Neil S, Ormond D, Price C, Rabbinowitsch E, Rutter S, Sanders M, Saunders D, Seeger K, Sharp S, Simmonds M, Skelton J, Squares R, Squares S, Stevens K, Unwin L, Whitehead S, Barrell BG, Maskell DJ: Comparative analysis of the genome sequences of Bordetella pertussis, Bordetella parapertussis and Bordetella bronchiseptica. Nat Genet 2003, 35:32-40.

49. Chain PS, Carniel E, Larimer FW, Lamerdin J, Stoutland PO, Regala WM, Georgescu AM, Vergez LM, Land ML, Motin VL, Brubaker RR, Fowler J, Hinnebusch J, Marceau M, Medigue C, Simonet M, ChenalFrancisque V, Souza B, Dacheux D, Elliott JM, Derbise A, Hauser LJ, 
Garcia E: Insights into the evolution of Yersinia pestis through whole-genome comparison with Yersinia pseudotuberculosis. Proc Natl Acad Sci U S A 2004, I O I: I3826-I 383 I.

50. Rohmer L, Fong C, Abmayr S, Wasnick M, Larson Freeman TJ, Radey M, Guina T, Svensson K, Hayden HS, Jacobs M, Gallagher LA, Manoil C, Ernst RK, Drees B, Buckley D, Haugen E, Bovee D, Zhou Y, Chang J, Levy R, Lim R, Gillett W, Guenthener D, Kang A, Shaffer SA, Taylor G, Chen J, Gallis B, D'Argenio DA, Forsman M, Olson MV, Goodlett DR, Kaul R, Miller SI, Brittnacher MJ: Comparison of Francisella tularensis genomes reveals evolutionary events associated with the emergence of human pathogenic strains. Genome Biol 2007, 8:RI02.

51. Vezzi A, Campanaro S, D'Angelo M, Simonato F, Vitulo N, Lauro FM, Cestaro A, Malacrida G, Simionati B, Cannata N, Romualdi C, Bartlett $\mathrm{DH}$, Valle G: Life at depth: Photobacterium profundum genome sequence and expression analysis. Science 2005, 307:|1459-|46|.

52. Heidelberg JF, Eisen JA, Nelson WC, Clayton RA, Gwinn ML, Dodson RJ, Haft DH, Hickey EK, Peterson JD, Umayam L, Gill SR, Nelson KE, Read TD, Tettelin H, Richardson D, Ermolaeva MD, Vamathevan J, Bass S, Qin H, Dragoi I, Sellers P, McDonald L, Utterback T, Fleishmann RD, Nierman WC, White O, Salzberg SL, Smith HO, Colwell RR, Mekalanos J], Venter JC, Fraser CM: DNA sequence of both chromosomes of the cholera pathogen Vibrio cholerae. Nature 2000, 406:477-483.

53. Makino K, Oshima K, Kurokawa K, Yokoyama K, Uda T, Tagomori K, lijima Y, Najima M, Nakano M, Yamashita A, Kubota Y, Kimura S, Yasunaga T, Honda T, Shinagawa H, Hattori M, lida T: Genome sequence of Vibrio parahaemolyticus: a pathogenic mechanism distinct from that of $\mathbf{V}$ cholerae. Lancet 2003, 36 I:743-749.

54. Chen CY, Wu KM, Chang YC, Chang CH, Tsai HC, Liao TL, Liu YM, Chen HJ, Shen AB, Li JC, Su TL, Shao CP, Lee CT, Hor LI, Tsai SF: Comparative genome analysis of Vibrio vulnificus, a marine pathogen. Genome Res 2003, 13:2577-2587.

55. Chen L, Brugger K, Skovgaard M, Redder P, She Q, Torarinsson E, Greve B, Awayez M, Zibat A, Klenk HP, Garrett RA: The genome of Sulfolobus acidocaldarius, a model organism of the Crenarchaeota. / Bacteriol 2005, 187:4992-4999.

56. Kawarabayasi $Y$, Hino $Y$, Horikawa $H$, Jin-no K, Takahashi M, Sekine M, Baba S, Ankai A, Kosugi H, Hosoyama A, Fukui S, Nagai Y, Nishijima K, Otsuka R, Nakazawa H, Takamiya M, Kato Y, Yoshizawa T, Tanaka T, Kudoh Y, Yamazaki J, Kushida N, Oguchi A, Aoki K, Masuda S, Yanagii M, Nishimura M, Yamagishi A, Oshima T, Kikuchi H: Complete genome sequence of an aerobic thermoacidophilic crenarchaeon, Sulfolobus tokodaii strain7. DNA Res 200I, 8:123-140.

57. She Q, Singh RK, Confalonieri F, Zivanovic Y, Allard G, Awayez MJ, Chan-Weiher CC, Clausen IG, Curtis BA, De Moors A, Erauso G, Fletcher C, Gordon PM, Heikamp-de Jong I, Jeffries AC, Kozera CJ. Medina N, Peng X, Thi-Ngoc HP, Redder P, Schenk ME, Theriault C Tolstrup N, Charlebois RL, Doolittle WF, Duguet M, Gaasterland T, Garrett RA, Ragan MA, Sensen CW, Van der Oost J: The complete genome of the crenarchaeon Sulfolobus solfataricus P2. Proc Natl Acad Sci U S A 200I, 98:7835-7840.

58. Ng WV, Kennedy SP, Mahairas GG, Berquist B, Pan M, Shukla HD Lasky SR, Baliga NS, Thorsson V, Sbrogna J, Swartzell S, Weir D, Hall J, Dahl TA, Welti R, Goo YA, Leithauser B, Keller K, Cruz R, Danson M], Hough DW, Maddocks DG, Jablonski PE, Krebs MP, Angevine CM, Dale H, Isenbarger TA, Peck RF, Pohlschroder M, Spudich JL, Jung KW, Alam M, Freitas T, Hou S, Daniels CJ, Dennis PP, Omer AD, Ebhardt H, Lowe TM, Liang P, Riley M, Hood L, DasSarma S: Genome sequence of Halobacterium species NRC-I. Proc Natl Acad Sci U S A 2000, 97:|2176-12181.

59. Reznikoff WS, Bordenstein SR, Apodaca J: Comparative sequence analysis of IS50/Tn5 transposase. J Bacteriol 2004 I 86:8240-8247.

60. Vilei EM, Nicolet J, Frey J: IS I 634, a novel insertion element creating long, variable-length direct repeats which is specific for Mycoplasma mycoides subsp. mycoides small-colony type. J Bacteriol 1999, I81:1319-1323.

6I. Plikaytis BB, Crawford JT, Shinnick TM: ISI 549 from Mycobacterium smegmatis forms long direct repeats upon insertion. Bacteriol 1998, 180:1037-1043.

62. Wagner A, Lewis C, Bichsel M: A survey of bacterial insertion sequences using IScan. Nucleic Acids Res 2007, 35:5284-5293.
63. The Belgian EMBnet node (BEN) [http://www.be.embnet.org/]

64. Thompson JD, Higgins DG, Gibson TJ: CLUSTAL W: improving the sensitivity of progressive multiple sequence alignment through sequence weighting, position-specific gap penalties and weight matrix choice. Nucleic Acids Res 1994, 22:4673-4680.

65. Morgenstern B: DIALIGN 2: improvement of the segment-tosegment approach to multiple sequence alignment. Bioinformatics 1999, 15:211-218.

66. Gotoh O: A weighting system and algorithm for aligning many phylogenetically related sequences. Comput Appl Biosci 1995, II:543-55।

67. Edgar RC: MUSCLE: multiple sequence alignment with high accuracy and high throughput. Nucleic Acids Res 2004, 32:1792-1797.

68. Notredame C, Higgins DG, Heringa J: T-Coffee: A novel method for fast and accurate multiple sequence alignment. J Mol Biol 2000, 302:205-217

69. Wallace IM, O'Sullivan O, Higgins DG, Notredame C: M-Coffee: combining multiple sequence alignment methods with $T$ Coffee. Nucleic Acids Res 2006, 34:1692-1699.

70. Clamp M, Cuff J, Searle SM, Barton GJ: The Jalview Java alignment editor. Bioinformatics 2004, 20:426-427.

7I. Page RD: TreeView: an application to display phylogenetic trees on personal computers. Comput Appl Biosci 1996, I 2:357-358.

72. Enright AJ, Van Dongen S, Ouzounis CA: An efficient algorithm for large-scale detection of protein families. Nucleic Acids Res 2002, 30:1575-1584

73. ACLAME [http://aclame.ulb.ac.be/]

74. Altschul SF, Madden TL, Schaffer AA, Zhang J, Zhang Z, Miller W, Lipman D]: Gapped BLAST and PSI-BLAST: a new generation of protein database search programs. Nucleic Acids Res 1997, 25:3389-3402.

75. Kang Y, Durfee T, Glasner JD, Qiu Y, Frisch D, Winterberg KM, Blattner FR: Systematic mutagenesis of the Escherichia coli genome. J Bacteriol 2004, I 86:492 I-4930.

76. Shevchenko Y, Bouffard GG, Butterfield YS, Blakesley RW, Hartley JL, Young AC, Marra MA, Jones SJ, Touchman JW, Green ED: Systematic sequencing of cDNA clones using the transposon Tn5. Nucleic Acids Res 2002, 30:2469-2477.

77. Goryshin IY, Miller JA, Kil YV, Lanzov VA, Reznikoff WS: Tn5/IS50 target recognition. Proc Natl Acad Sci U S A 1998, 95: I07| 6- I072I.
Publish with Biomed Central and every scientist can read your work free of charge

"BioMed Central will be the most significant development for disseminating the results of biomedical research in our lifetime. "

Sir Paul Nurse, Cancer Research UK

Your research papers will be:

- available free of charge to the entire biomedical community

- peer reviewed and published immediately upon acceptance

- cited in PubMed and archived on PubMed Central

- yours - you keep the copyright

Submit your manuscript here:

http://www.biomedcentral.com/info/publishing_adv.asp
BioMedcentral 